Premiere Educandum: Jurnal Pendidikan Dasar dan Pembelajaran

Volume 8(1) 54 - 59 Juni 2018

Copyright (C2018 Universitas PGRI Madiun

ISSN: 2088-5350 (Print) / ISSN: 2528-5173 (Online)

Available at: http://e-journal.unipma.ac.id/index.php/PE

Doi: $10.25273 /$ pe.v8i1.2366

\title{
Peningkatan ketrampilan senam lantai siswa kelas VI SDN Dempelan 01 melalui pembelajaran langsung dengan metode JIGSAW
}

\author{
Y Yusuf \\ SDN 01 Dempelan, Kabupaten Madiun \\ email: yusufpenjaskes@gmail.com
}

\begin{abstract}
This study aims to improve the gymnastics skills of grade 6 students at SDN 01 Dempelan, Madiun District. This study is a classroom action research conducted in the academic year 2016/2017 with 14 students as respondents. Actions performed as much as two cycles, the results obtained students' floor gymnastics skills have increased. Comparison of pre-cycle scores, cycle I and cycle II of. 63,90; 69,37; and 76.51. Skill in rolling movements, performing candlelight movements and performing split and wheeling movements have increased
\end{abstract}

Keywords: floor gymnastic skills; classroom action research; jigsaw

\section{Abstrak}

Penelitian ini bertujuan untuk mengingkatkan keterampilan senam lantai siswa kelas VI di SDN 01 Dempelan Kabupaten Madiun. Penelitian ini merupakan penelitian tindakan kelas yang dilaksanakan pada tahun pelajaran 2016/2017 dengan 14 siswa sebagai responden. Tindakan yang dilakukan sebanyak dua siklus, hasil yang didapatkan keterampilan senam lantai siswa mengalami peningkatan. Perbandingan skor pra siklus, siklus I dan siklus II sebesar. 63,90; 69,37; dan 76,51. Keterampilan melakukan gerakan berguling, melakukan gerakan sikap lilin dan melakukan gerakan split dan meroda mengalami peningkatan.

Kata Kunci: keterampilan senam lantai; penelitian tindakan kelas; jigsaw

Histori artikel : disubmit pada 20 Maret 2018; direvisi pada 8 Mei 2018; diterima pada 21 Mei 2018

\section{A. PENDAHULUAN}

Pembelajaran pendidikan jasmani, olahraga dan kesehatan menekankan pada pemberian pengalaman langsung untuk mengembangkan kompetensi agar siswa mampu mendorong pertumbuhan fisik, perkembangan psikis, keterampilan motorik, pengetahuan dan penalaran, penghayatan nilai-nilai, serta pembiasaan pola hidup sehar yang bermuara untuk merangsang pertumbuhan dan perkembangan fisik dan psikis yang seimbang. Kecakapan berolahraga yang ditumbuhkan pada siswa merupakan sumbangan mata pelajaran pendidikan jasmani, olahraga dan kesehatan kepada pencapaian kecakapan hidup yang ingin dicapai melalui kurikulum (Mahendra, 2008).

Pembelajaran pendidikan jasmani terdapat bermacam-macam cabang olahraga dan permainan bagi siswa sekolah dasar, salah satunya adalah cabang senam. (Sari, Sugiarto, \& Purnami, 2003) senam merupakan sekumpulan kegiatan yang mengandalkan aktifitas fisik yang bermanfaat untuk mengembangkan komponen fisik dan 
kemampuan gerak yang disusun secara sistematis dan terencana untuk mencapai suatu tujuan tertentu. Senam lantai merupakan satu dari rumpun senam yang aktivitas gerakannya terdiri dari berbagai variasi yang dilakukan di lantai atau matras yang digunakan sebagai alasnya.

Dalam setiap proses pembelajaran/pelatihan, setiap cabang olah raga memerlukan keterampilan, keberanian, kesenangan dan kepercayaan diri yang tinggi tertentu dalam melakukan agar hasilnya bisa maksimal. (Sujadi, 2008). Keterampilan senam lantai di sekolah dapat dijadikan sarana untuk meningkatkan kesegaran jasmani dan kesehatan siswa. Selain itu senam lantai juga dapat dijadikan sebagai alat untuk melatih kemampuan jasmani seperti kecepatan, kelincahan, keseimbangan, daya tahan, kekuatan dan juga melatih keberanian serta percaya diri (Wuryantoro \& Muktiani, 2011).

Permasalahan yang dihadapi dalam pelaksanaan pembelajaran senam adalah adanya anggapan bahwa senam itu merupakan materi ajar yang tidak menarik, sulit, menakutkan serta resiko terjadinya cedera tinggi, ditambah lagi dengan peralatannya yang mahal harganya dan pelaksanaannya harus di ruangan (hall). Guru pendidikan jasmani perlu memahami bahwa senam di sekolah dasar bukanlah senam yang bersifat perlombaan dengan tingkat kesulitan yang tinggi, serta memerlukan peralatan yang sulit didapat serta mahal harganya dan harus dilakukan di dalam ruangan khusus senam. Pemikiran yang demikian adalah keliru. Senam di sekolah dasar prinsipnya yaitu membelajarkan pola gerak dominan dalam senam, serta pengembangannya yang disesuaikan dengan tingkat perkembangan kemampuan siswa (Suharjana, Sriawan, \& Pambudi, 2010).

Temuan dilapangan terkait dengan keterampilan anak-anak kelas IV dalam melakukan gerakan senam lantai masih perlu ditingkatkan, karena belum semua murid memiliki keberanian, kesenangan dan percaya diri dalam melakukan gerakan senam lantai. Melalui penerapan pembelajaran penjaskes dengan menerapkan model tim ahli (Jigsaw) ini diharapkan dapat meningkarkan keterampilan senam lantai siswa.

\section{B. METODE PENELITIAN}

Penelitian ini dilaksanakan di Kelas VI SDN Dempelan 01 Kabupaten Madiun, pada mata pelajaran Pendidikan jasmani, olahraga dan kesehatan dan pada Standar kompetensi dasar Mempraktikkan kombinasi gerak senam lantai dan senam ketangkasan dengan konsisten, dan kontrol yang baik, serta nilai keselamatan, disiplin, dan kerjasama. Pelaksanaan tindakan kelas berlangsung pada kegiatan pembelajaran pendidikan jasmani, olahraga dan kesehatan pada semester 2 tahun pelajaran 2016/2017. Tiga aspek utama yang akan dibahas dalam penelitian ini adalah gerakan berguling, sikap lilin, dan gerakan split dan meroda. Siklus penelitian kelas yang direncanakan seperti pada gambar 1 .

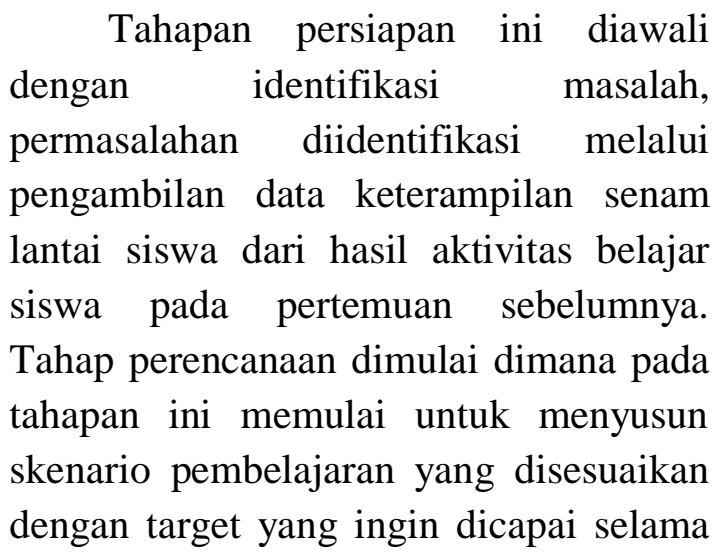


pelaksanaan penelitian tindakan kelas dilakukan. Aksi, tahapan aksi disini merupakan tahapan pelaksanaan kegiatan pembelajaran dengan menyesuaikan rencana pembelajaran yang telah disusun selama proses perencanaan dengan tujuan mencapai target minimal yang telah ditetapkan. Tahapan selanjtunya, tahapan evaluasi pada tahapan ini dilakukan evaluasi terhadap hasil aksi pada tahapan sebelumnya meliputi hasil ketrampilan senam lantai dan evaluasi dari ketercapaian perencaan sesuai target yang diterapkan.

Target minimal yang ditetapkan dalam penelitian tindakan kelas ini yakni minimal rata-rata keterampilan senam siswa mencapai 75,00. Siklus penelitian tindakan akan dihentikan apabila hasil evaluasi dari setiap siklus telah mencapai target yang telah ditentukan. Target 75,00 ditetapkan dengan didasari kondisi siswa yang dijadikan responden, dan kurikulum pembelajaran yang harus diselesaikan selama 1 semester.

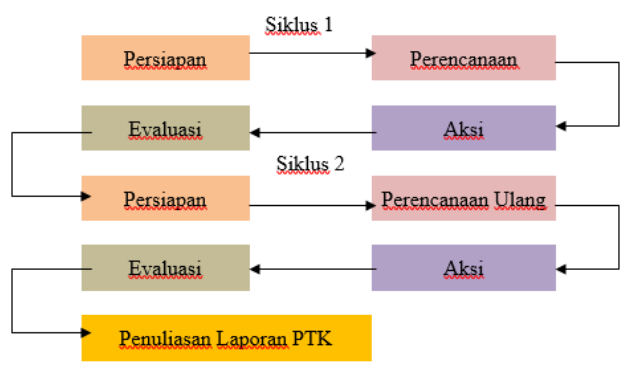

Gambar 1. Siklus penelitian tindakan kelas

\section{HASIL DAN PEMBAHASAN}

Proses pembelajaran ini dimulai dengan pretest untuk mengetahui baseline kemampuan yang dimiliki oleh siswa. Tes awal yang dilakukan ini untuk mengetahui kemampuan siswa dalam melakukan senam lantai khusunya untuk tiga gerakan yang akan dijadikan fokus dalam penelitian ini yakni gerakan berguling, gerakan sikap lilin, dan gerakan split dan meroda. Adapun hasil test terhadap 14 respoden untuk mengetahui kemampuan senam lantai seperti pada gambar 2 .

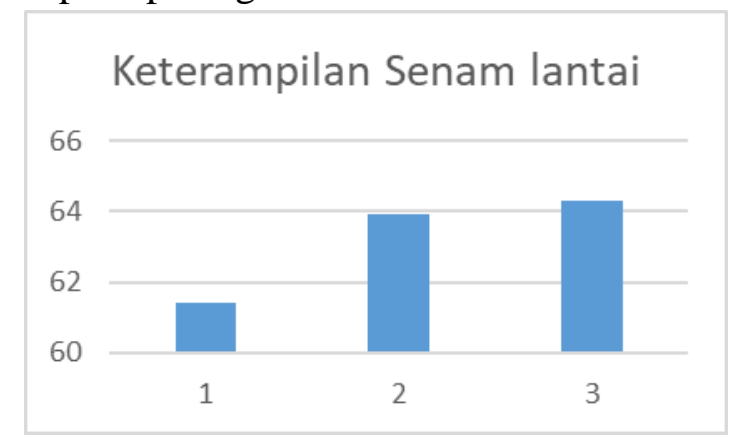

Gambar 2. Keterampilan 3 aspek senam lantai pra Siklus

Aspek penilaian yang pertama dilakukan untuk mengetahui keterampilan senam lantai adalah keterampilan gerakan berguling dengan rata-rata skor 61, 42 dari 14 responden siswa. Keterampilan melakukan gerakan sikap lilin dengan rata-rata skor dari 14 siswa sebesar 63,92. Sedangkan untuk rata-rata kemampuan melakukan gerakan split dan meroda sebesar 64,28. Data-data tersebut yang nantinya dijadikan dasar untuk mengetahui sejauh mana penerapan model Jigsaw ini mampu meningkatkan keterampilan senam lantai siswa kelas VI.

\section{Siklus I}

Hasil keterampilan pada siklus I untuk rata-rata skor keterampilan gerakan berguling sebesar 67,85 , rata-rata skor keterampilan gerakan sikap lilin sebesar 69,28 dan rata-rata skor ketrampilan gerakan split dan meroda sebesar 70. Data tersebut didapat setelah dilakukannya tindakan siklus I terhadap 14 orang responden. Adapun hasil keterampilan melakukan senam lantai pada siswa kelas VI SDN 01 Dempelan 
sebelum dan sesudah diberikan tindakan tercermin pada gambar 3 .

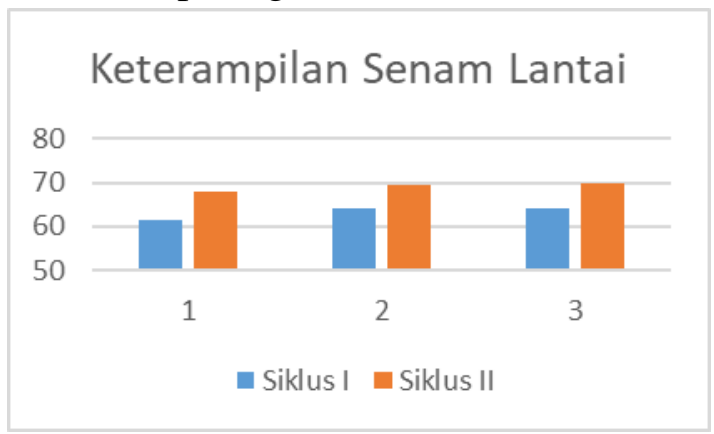

Gambar 3. Keterampilan 3 aspek senam lantai pra Siklus dan Siklus I

Keterampilan senam lantai yang pertama ialah keterampilan gerakan berguling atau roll yang meliputi sikap permulaan jongkok yang seimbang, menggunakan tengkuk sebagai tumpuan dalam berguling, sikap saat berguling tangan memeluk kedua kaki dan diakhiri dengan sikap jongkok yang seimbang. Suksesnya gerakan roll depan terletak pada tumpuan dan sikap berguling (Permatasari, Priyono, \& Rustiadi, 2016). Data pra siklus dan siklus I mengalamai peningkatan, mayoritas dari 14 responden mengalami skor peningaktan antara 5-10. Hal ini disebabkan siswa yang sebelumnya memiliki keraguan dalam melaksanakan roll/berguling sedikit demi sedikit telah muncul keberanian dan keyakinannya bahwa mampu melakukan gerakan tersebut.

Untuk mendapatkan hasil belajar sikap lilin yang baik, tentunya memerlukan kondisi fisik yang baik. Hal ini disebabkan karena lemahnya kondisi fisik yaitu kelentukan dan kekuatan otot tidak berfungsi. Kelentukan gerak tubuh pada persendian tersebut, sangat dipengaruhi oleh elastisitas otot, tendon dan ligament di sekitar sendi serta kualitas sendi itu sendiri. Sedangkan kekuatan otot adalah tenaga, gaya atau ketegangan yang dapat dihasilkan oleh otot atau sekelompok otot pada suatu kontraksi dengan beban maksimal (Yuarsa, Purnomo, \& Yunitaningrum, 2013). Kemampuan siswa kelas VI dalam melakukan gerakan sikap lilin mengalami peningkatan sebesar 5,35 dari sebelum siklus I 63,92 dan setelah siklus I menjadi 69,28 .

Kesalahan yang sering terjadi saat melakukan gerakan meroda adalah anak ingin menempatkan tapak tangan pertama secepat mungkin, sehingga ia menyiasati dengan jalan pintas yang mengakibatkan lutut kaki (sebelah arah meroda) terlalu dibengkokkan (Sari et al., 2003). Merujuk pada kesalahan umum yang terjadi tersebut disiasati pada siklus satu sehingga kesalahan yang biasa muncul tersebut tidak diulangi oleh peserta didik. Skor kemampuan split dan meroda mengalami peningkatakan skor yang cukup signifikan jika diperhatikan pada gambar 3 .

\section{Siklus II}

Berdasarkan hasil refleksi pada siklus I dirasa masih ada yang belum mengalami progress peningkatan yang maksimal maka tindakan dilanjutkan pada siklus II. Perbadingan hasil dari dari pelaksanaan pra siklus, siklus I dan siklus II terlihat pada gambar 4 .

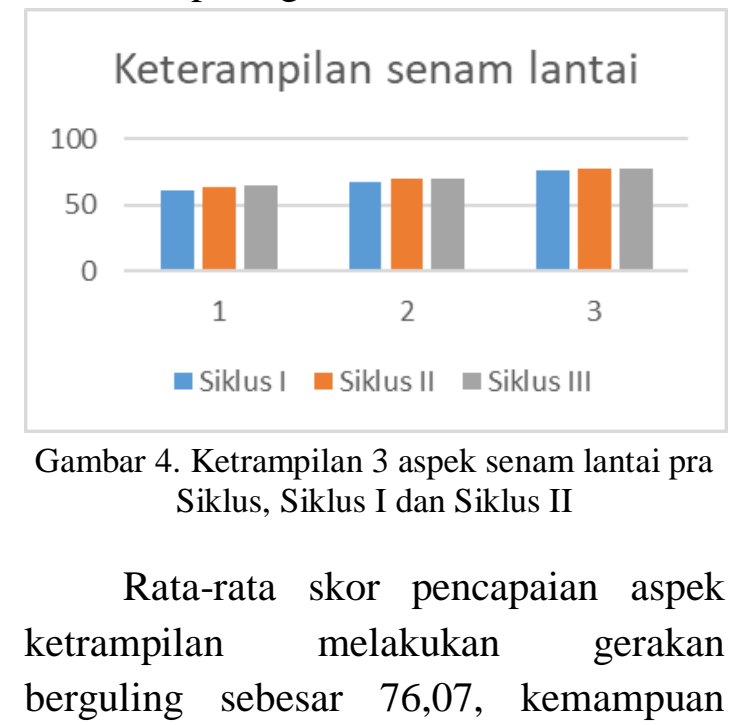


melakukan gerakan lilin sebesar 77,14 dan kemampuan melakukan gerakan split dan meroda sebesar 77,5. Berdasarkan hasil refleksi hasil ini yang dirasa merupakan hasil maksimal yang dapat diraih dalam penelitian tindakan yang telah dilakukan dengan mempertimbangkan aspek yang menjadi varibel dalam penelitian.

Skor total yang menjadi representasi dari pelaksanaan tindakan dalam rangka peningkatan keterampilan senam lantai siswa kelas VI SDN 01 Dempelan tercermin pada tabel 1 .

Tabel 1. Perbandingan rata-rata keterampilan senam lantai siswa

\begin{tabular}{ccc}
\hline \multicolumn{3}{c}{ Nilai rata-rata } \\
\hline Pra Siklus & Siklus I & Siklus II \\
\hline 63,90 & 69,37 & 76,51 \\
\hline Terdapat & peningkatan & skor
\end{tabular}

keterampilan senam lantai dari pra siklus, siklus I dan siklu II yang mencerminkan terlaksanya proses tindakan dalam rangka meningkatkan keteampilan senam lantai siswa. Pembelajaran langsung tipe kooperatif JIGSAW dipilih dilandasi pelaksanaan pembelajaran penjaskes di SD yang dilaksanakan secara menarik yang dikemas dalam sebuah permainan. Hal ini sesuai dengan teori dari John Locke (dalam Soemitro, 1992: 3) ia meyakini bahwa bermain dapat membantu dalam usaha mencapai tujuan pendidikan. Peningkatan keterampilan senam ini selain dikarenakan penerapan pembelajaran jigsaw cocok untuk pembelajaran penjaskes/olahraga (Munasih, 2016; Wijaya \& Ferianto T.K, 2017). Mengemas kegiatan peningkatan keterampilan/kemapuan olahraga pada siswa SD dapat dilakukan dengan pembelajaran langsung salah satunya dengan menerapkan pembelajaran berbasis JIGSAW.

\section{SIMPULAN}

Pembelajaran langsung dengan metode Jigsaw yang diterapkan dalam pembelajaran penjaskes dapat meningkatkan keterampilan senam lantai siswa kelas VI SDN 01 Dempelan Kecamatan Madiun Kabupaten Madiun pada tahun pelajaran 2016/2017. Peningkatan keterampilan senam lantai tersebut mencangkup keterampilan melakukan gerakan berguling, melakukan gerakan sikap lilin, dan melakukan gerakan split dan meroda.

\section{DAFTAR RUJUKAN}

Mahendra, A. (2008). Pengembangan Kecakapan Hidup dalam Pendidikan Jasmani Pengembangan Kecakapan Hidup dalam Pendidikan Jasmani, 18-19.

Munasih, S. (2016). Meningkatkan kreatifitas gerak dasar lempar tangkap bola lunak melalui pembelajaran jigsaw. Didaktikum: Jurnal Penelitian Tindakan Kelas, 17(1), 56-63.

Permatasari, D. aji, Priyono, B., \& Rustiadi, T. (2016). Journal of Physical Education, Sport, Health and Recreations. Jurnal of Physiscal Education, Sport, Health and Recreations, 5(3), 5-8.

Sari, W. K. S., Sugiarto, T., \& Purnami, S. (2003). Rangkaian sederhana siswa kelas viii di SMP Negeri 2. Pendidikan Jasmani, 26(1). https://doi.org/http://dx.doi.org/10.1 7977/pj.v26i1.7726.g3545

Suharjana, F., Sriawan, S., \& Pambudi, A. F. (2010). Pelatihan inovasi pembelajaran senam dengan pendekatan pola gerak dominan bagi guru-guru Penjasorkes SD di Kecamatan Pejagoan Kabupaten Kebumen. Yogyakarta.

Sujadi, U. (2008). Journal of Physical 
Education. Journal of Physical Education, Sports, Health and Recreations, 17(1), 107-116. Retrieved from http://www.periodicos.uem.br/ojs/in dex.php/RevEducFis/article/view/33 77

Soemitro. (1992). Permainan kecil. Jakarta: Departemen Pendidikan dan Kebudayaan Direktorat Jenderal Pendidikan Tinggi Proyek Bimbingan Tenaga Kependidikan

Wijaya, D. H., \& Ferianto T.K, B. (2017). Perbandingan model pembelajaran kooperatif tipe tgt (team games tournament) dengan tipe jigsaw terhadap motivasi belajar siswa dalam pembelajaran pendidikan jasmani, olahraga, dan kesehatan (Studi pada siswa kelas XI SMA Negeri 1 Srengat). Jurnal Pendidikan Olahraga Dan Kesehatan, 5(2), 297-305.

Wuryantoro, K., \& Muktiani, N. R. (2011). Meningkatkan Keterampilan Senam Meroda Melalui Permainan Tali Pada Siswa Kelas Viiia Mts Ma - Arif Nu. Jurnal Pendidikan Jasmani Indonesia, 8(2), 89-99.

Yuarsa, H., Purnomo, E., \& Yunitaningrum, W. (2013). Hubungan kelentukan togok dan kekuatan otot lengan terhadap hasil belajar sikap lilin Hendra Yuarsa, Edi Purnomo,Wiwik Yunitaningrum. Jurnal Pendidikan Dan Pembelajaran, 2(2). 